Article

\title{
Developing a Fanbase in Niche Sport Markets: An Examination of NHL Fandom and Social Sustainability in the Sunbelt
}

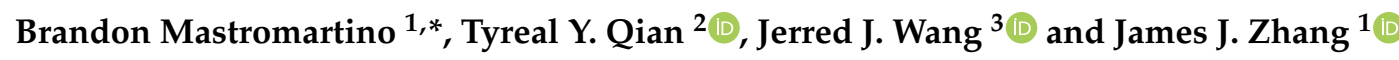 \\ 1 Department of Kinesiology, University of Georgia, Athens, GA 30602, USA; jamesz48@uga.edu \\ 2 School of Kinesiology, Louisiana State University, Baton Rouge, LA 70803, USA; yqian@lsu.edu \\ 3 Department of Sport Management, Wellness, and Physical Education, University of West Georgia, \\ Carrollton, GA 30117, USA; jwang@westga.edu \\ * Correspondence: bmastro@uga.edu; Tel.: +1-706-461-8388
}

Received: 29 December 2019; Accepted: 29 January 2020; Published: 4 February 2020

\begin{abstract}
In the modern day sport marketplace, professional sport teams face tough competition to build and sustain a viable fan base. This study sought to address three research questions: (a) what are the factors that contribute to the socialization of sports fans in niche sport markets? (b) How do team-led and fan-led initiatives work to socialize fans? Finally, (c) to what extent do the socialization factors affect identify as a sports fan for a niche sport and overall fan consumption behavior? A questionnaire was administered to 535 NHL fans and data were analyzed through conducting an Exploratory Factor Analysis, Exploratory Factor Analysis and Structural Equation Modeling. The most notable findings revealed that influences from family or media exposure did not play a factor in the socialization of these fans, signaling the uniqueness of Sunbelt regional marketplace and a departure from traditional beliefs. Discussions are focused on interpreting theoretical and practical implications for socializing individuals into being hockey fans, growing professional hockey, projecting sustainable development, and providing a framework for other sport leagues.
\end{abstract}

Keywords: fan socialization; sport marketing; consumer behavior; niche sports

\section{Introduction}

Approaching the third decade of the new millennium; the growth of professional sports may have reached the point of saturation [1], especially in the United States with the dominance of three professional leagues (National Football League, National Basketball Association, and Major League Baseball) and collegiate athletics; other leagues face major challenges in building up a fan base and growing their brands. In such a competitive market environment; a viable strategy for small or new leagues has been to add franchises in marketplaces where that sport does not have a long-standing tradition in an effort to tap into new areas and cultivate new fans. In order to have long term business success, it is vital for sport organizations to develop a sustainable model that will work to continue to build their fan base [2,3]. An example of this practice is when the National Hockey League (NHL) began to expand into the Sunbelt region of the United States in the early 1990s, a geographic region that is generally considered to stretch across the Southeastern and Southwestern U.S. This effort has continued until very recently, as evidenced in the Las Vegas expansion franchise that began to play in 2017 [4]. The term niche sports refers to sports that are not mainstream and do not have a mass audience appeal [5]. Although some research has classified the NHL among the mainstream sports in the U.S. [6], its appeal is largely in the Northeast and Midwest region of the country [7]. Some key traits of mainstream sports include "large fan bases; broad appeal; and widespread media coverage" 
while niche sports "receive limited fan support and media attention" [8]. This classification can put certain leagues in both categories; such as Major League Soccer (MLS), NHL; National Lacrosse League (NLL), and the National Association for Stock Car Auto Racing (NASCAR). These sports receive significant attention in certain geographic regions, and almost none in others, leading previous scholars to note that geographic regions must be considered when considering the classification of a sport as "niche" $[9,10]$. With such differences among sports, more research is needed on niche sports, especially in the role fan identity plays in the consumption of sport in niche markets [11].

The purpose of this study is to understand how and why individuals form an identity as a fan of sport teams in niche markets. Previous research shows that a fan's identification with the team is the most important element in sustaining one's continued consumption of the sport team [12]. Consumers today have a wide variety of options in their leisure activities but an identity as a sports fan can drive and sustain their consumer behavior. This study evaluates how one develops an identity as a fan of a team in niche sport markets and quantifies the outcomes of having an identity as a fan in such markets. Through an examination of NHL fans in the Sunbelt region, the current study was designed to build off the previous conceptualizations and establish an empirical framework of sport fan socialization in niche markets. It is expected that findings of this study would add to the existing literature on sport fan identification and provide insight for the NHL in building fan bases in unconventional markets, something other North American sport leagues may also find useful when attempting to grow in the shadow of the NFL, NBA, MLB, and college athletics.

\section{Theoretical Framework and Hypothesis Development}

Our theoretical framework is presented in Figure 1, and the formulation of the study hypotheses is laid out in the subsequent sections.

\subsection{Sport Fan Identification}

Sport organizations in niche sports markets need to develop a strong base of individuals who each identify as a fan of the team. Previous researchers have indicated that strong sport fan identification is positively associated with motivations to attend games and consume team-related products [12], and even leads to a lifelong allegiance to the team that goes beyond occasional attendance at games and purchases of goods. Developing a high level of fan identification is key to the sustainable business development of a professional sport team [13]. However, no one is 'born a fan' and often it is parents, especially fathers, who have a strong influence on whether an individual becomes a fan of a sport and/or a team [14-16]. Previous research posited that one of the most fundamental environmental causes of team identification is the process of 'socialization'. Factors that contribute to one's socialization are considered 'socialization agents', and some researchers have suggested that traditional socialization agents to sport fandom included influences from family, peers, school, community, and media [16-19]. Consistent with this notion, some researchers have delved into the process and outcomes of socialization of fans in niche sport markets. For instance, Mastromartino, Wann and Zhang [4] conducted a qualitative study and found that the first game experience, team success, media exposure, and influences from family and friends are particularly salient in terms of contributing to NHL fans' socialization in the Sunbelt region.

While previous researchers have made strong attempts to explore various perspectives that contribute to one's socialization process in niche sport markets, these studies primarily adopted a qualitative paradigm, tackled the issues by segmented approaches, and thus lacked a systematic integration $[4,20]$. It is also worth noting that previous studies on fan socialization predominantly focused on factors that came from within the fan (e.g., parent, school, friend influence). Rarely did they consider how impactful organizational efforts to build a fan base played a role in socialization. Moreover, considering that the conceptualizations were developed through qualitative investigations with specific socialization factors yet to be quantified, empirically tested, and inferentially confirmed, it is necessary to develop and test an empirical model that combines both fan-initiated and team-initiated 
factors to examine the salience and outcomes of socialization perspectives. Indeed, with leagues such as the NHL looking to marketplaces where the sport may be considered niche, much needs to be known about how individuals are socialized into fandom.

\subsection{Socialization Theory and Identity Formation}

Sport fans reinforce identification with a sport team by engaging in consumption behaviors, such as attending games or buying merchandise [21]. If organizations could better understand how that identity is formed, they could tailor marketing campaigns and outreach to better target those identity origin factors, also known as 'socialization agents'. Previous research has concluded that the main influences on one's socialization process includes the fan's family, peers, schoolmates, coaches, local community, media, team/league promotions, and playing experience [16-19,22]. Additionally, Hyatt, et al. [23] found that sometimes, it can be a child who socializes a parent into fandom. These results have held up over the years, yet with a changing sport consumption landscape and a focus on niche markets, these results may not be applicable. In addition, previous studies have mainly examined the socialization process from the perspective of the individual fan, without considering the impact of the efforts put forth by team management. There is no available tool to measure socialization that considers individual factors and team factors in the same model. Before examining the structural relationships between socialization agents and fans' consumption behaviors, it is necessary to first explicate the unique features of fan-initiated and team-initiated socialization agents.

Fan-initiated socialization agents are factors that come from the fan's environmental surroundings which are usually outside the direct control of the team [24]. The most prominent factor under this category includes influence of family and/or friends $[15,17,19,25]$. Next, the geographic region a fan grew up in can also play a role in becoming a fan of the local team [26,27]. Third, media exposure, primarily through various sources such as social media, online streaming, video gaming, and traditional media products such as television or radio, has been found to be an influential fan-initiated socialization agent $[4,28,29]$. Lastly, participation in a sport can lead one to develop an identity as a fan of a team in that sport and enjoy consuming the sport as well as participating in it [22,30].

Team-initiated socialization agents are influences that come directly from the sport team, and previous research has noted various ways sport organizations have an influence on the socialization of fans. One area a team can have influence on socialization is at the stadium, especially if the first game experience is made memorable [4,31]. Second, if the organization establishes a one-on-one relationship with an individual, it can be a pathway to fandom. This can be through direct interactions with players [16], or with members of the front office, such as a sales team member [20]. Third, team success is often found to have an influence on an individual developing an identity as a fan, specifically if that team has a past reputation of success (e.g., New York Yankees, Boston Celtics), or if the team was brought to their attention during a specific window of success (e.g., Golden State Warriors 2015-2018) $[19,26]$. The fourth factor under team-led initiatives is school programs. Increasingly, sport organizations are developing partnerships with local schools to gain awareness for their brand through educational programming and opportunities to learn the rules of a new sport and in turn open up an opportunity to socialize a young fan [32]. Lastly, unique promotions have been noted as a way in which organizations can have a direct influence on the socialization process. For example, Mastromartino, Zhang and Wann [20] highlight the Arizona Coyotes' jersey exchange program where parents can trade in an NHL jersey from any other team and receive authentic kids Coyotes jerseys for every child they bring with them.

In summary, given the diversity of socialization agents from both fan-initiated and team-initiated perspectives, it is imperative to understand how those factors play a role in fan socialization and the extent to which socialization in niche sport markets differs from traditional socialization literature. Based on previous literature and the need for a better understanding of sport fan socialization, the following research questions (RQ) are devised:

RQ1: What are the factors that contribute to the socialization of sports fans in niche sport markets? 
RQ2: How do team-led and fan-led initiatives work together to socialize fans?

RQ3: What extent do the socialization factors affect identity as a sports fan for a niche sport and overall fan consumption behavior?

\section{Materials and Methods}

The scale development, data collection, and analysis process for this study took place over five phases: (1) formulation of a preliminary scale, (2) content validity testing, (3) exploratory factor analysis, (4) confirmatory factor analysis, (5) structural equation modeling. Phase One in this process was to form a preliminary scale featuring socialization factors from previous studies as discussed in the literature review. Several sample items were developed under each construct to describe and measure various elements of each construct as noted in Table 1. Since a scale measuring the constructs of sport fan socialization in niche markets does not exist, this study modified similar scale items and created new ones that are appropriate for this study.

Phase Two aimed to ensure the construct validity of this study [33]. The sample items for each construct and dependent variable items were sent to a panel of experts to determine the content validity of the created items, as suggested by Hardesty and Bearden [34]. After ensuring validity of the items, a questionnaire was developed following guidelines from Andrew, et al. [35] that asked participants to measure all items on a seven-point Likert-type scale ranging from (1) strongly disagree to (7) strongly agree.

To address RQ1, Phase Three began and data were collected for an exploratory analysis (EFA). This allowed us to undercover the underlying structure of the large set of variables and generate a theoretical model that was tested in the next phase [36]. The sample of this study came from a population of fans of NHL teams in the Sunbelt region and purposive sampling was used as it is particularly useful when examining a specific case, such as this study aims to do. Participants were recruited on popular online NHL fan communities such as Reddit.com/r/hockey and hfboards.com, as it has been shown that online fan message boards are suitable places to recruit identified sports fans [29]. The survey was administered through Qualtrics and participants were asked to complete sociodemographic and fan behavior questions in addition to measuring the constructs of socialization. After an EFA, a confirmatory factor analysis (CFA) was performed to test whether the data fits in the measurement model that is hypothesized [36]. Participant recruitment and survey administration were the same as the CFA. The data collected for the EFA and CFA allowed for development of the theory of constructs of fan socialization in niche sport markets and lead to Phase Six, which is addressing RQ3 and examining how each construct of socialization impacts fan consumer behavior through structural equation modeling (SEM). The consumer behavior outcome items were developed from previous research on consumption behavior of sport fans in niche markets $[4,10]$.

Analysis for the EFA was conducted with the statistical software SPSS. This approach "allows for the computation of a wide range of indices of the goodness of fit of the model [and] permits statistical significance testing of factor loadings and correlations among factors and the computation of confidence intervals" [37] To determine the appropriate factors to retain, the Kasier criterion [38] and the scree test [39] were adopted. Determination of the factors and items followed Kaiser [40], where a factor should have eigenvalue equal to or greater than 1.0, and Nunnally and Bernstein [41], where an item should have a factor loading equal to or greater than 0.40 . The retained factors and items were related to the theoretical context of this study.

Next, analysis of the CFA occurred by using the latest version of AMOS software. In order to determine the goodness of fit from the EFA, the following statistical tests were examined: chi-square statistic $\left(\chi^{2} \chi^{2}\right)$, normed chi-square $\left(\chi^{2} / d f \chi^{2} / d f\right)$, root mean square error of approximation (RMSEA), standardized root mean residual (SRMR), and comparative fit index (CFI). RMSEA value was examined using guidelines from $\mathrm{Hu}$ and Bentler [42] where RMSEA values less than 0.06 show a close fit, between $0.06-0.08$ shows acceptable fit, between 0.08 and 0.10 shows mediocre fit, and greater than 0.10 indicates an unacceptable fit of the data. The CFI highlights the improvement in fit of the model from this 
research compared to a null model and if the value of the CFI is larger than 0.90 it will indicate an acceptable fit (Kline, 2005). Additionally, Conbach's alpha scores with a cut-off of 0.70 [41] and average variance extracted (AVE) values with a cut-off of 0.50 [43] were calculated for the composite reliability assessment and discriminant validity of the constructs. Lastly, comparisons of squared correlations among factors were examined using guidelines from Kline (2005) that suggest discriminate validity can be established if correlations among constructs are less than 0.85 .

After the EFA and CFA, this study commenced with structural equation modeling (SEM). SEM is commonly used in social sciences because of its ability to impute relationships between unobserved constructs (socialization agents) from observable variables (fan identity and behaviors) [44]. SEM was completed using guidelines from Kline [44]. Although the results examine the socialization agents under two categories, namely team and fan-initiated agents, it was the consumers who completed the survey and it was not intended for the respondents to consciously distinguish between the two perspectives. Thus, both perspectives were considered in the scale development but within first order constructs.

\section{Results}

\subsection{Descriptive Statistics}

While there were 955 individuals who started the survey, a total of 535 completed it, for a completion rate of $56 \%$. The average age of participants was 29.4 with a range from $18-67$ years old. When looking at gender, $80 \%(n=429)$ identified as male, $19 \%(n=103)$ as female, and $1 \%(n=3)$ chose not to respond. The household income of participants was fairly balanced among the categories with $11 \%(n=57)$ making below $\$ 25 \mathrm{~K}, 19 \%(n=101)$ making between $\$ 25 \mathrm{~K}-\$ 49 \mathrm{~K}, 16 \%(n=88)$ between $\$ 50 \mathrm{~K}-\$ 74 \mathrm{~K}, 17 \%(n=92)$ between $\$ 75 \mathrm{~K}-\$ 99 \mathrm{~K}, 18 \%(n=96)$ between $\$ 100 \mathrm{~K}-\$ 149 \mathrm{~K}$, and $16 \%(n=86)$ at $\$ 150 \mathrm{~K}$ or above. Of the participants, $62 \%$ held at least a college degree.

\subsection{Exploratory Factor Analysis}

For an exploratory factor analysis (EFA), one half of the data was randomly divided for a sample of 268 participants. The initial EFA yielded 10 factors with 29 items, which explained a total variance of $72.8 \%$. However, several items were cross-loaded on different factors and those items were removed in a follow-up run of the EFA. This EFA yielded seven factors with 24 items explaining a total variance of $81.3 \%$. The Kaiser-Meyer-Olkin measure of sampling adequacy was above $0.600(0.804)$ and $p<0.05$ for Barrlett's Test of Sphericity, indicating an EFA is appropriate for this data. The scree plots also indicated that a seven-factor model is appropriate for this data. Following guidelines from Hair Jr, et al. [45], each item has at least three loading factors and each factor has a loading of above 0.40 [41]. The findings of the EFA can be found in Table 1 .

\subsection{Confirmatory Factor Analysis}

A confirmatory factor analysis (CFA) was conducted using the most recent version of AMOS from IBM SPSS with the second half of the data set $(N=267)$. The CFA was conducted using the seven-factor 24-item model derived from the EFA. In this analysis, the RMSEA value indicated an acceptable fit (RMSEA = 0.069) [42]. Additionally, according to guidelines from $\mathrm{Hu}$ and Bentler [42], the CFI $($ CFA $=0.94)$ was above the recommended cut-off value of 0.90 , indicating the model is a strong fit for this data. Other fit indices showed an acceptable fit, such as the normed chi-square $\left(x^{2} / d f=2.27\right)$, which was below the recommended cut-off value of 3.0 [46]. Considering the metrics derived from this CFA, this model can be deemed an acceptable measurement model. 
Table 1. Factor Pattern Matrix.

\begin{tabular}{|c|c|c|c|c|c|c|c|}
\hline Factors & F1 & F2 & F3 & F4 & F5 & F6 & F7 \\
\hline Individual Relationship (4 items) & & & & & & & \\
\hline Someone who works for the organization is available to me often & 0.881 & & & & & & \\
\hline $\begin{array}{l}\text { There is regular communication between myself and someone who works } \\
\text { for the organization }\end{array}$ & 0.841 & & & & & & \\
\hline $\begin{array}{l}\text { I have opportunities to meet/communicate with someone who works for } \\
\text { the organization }\end{array}$ & 0.798 & & & & & & \\
\hline $\begin{array}{c}\text { There is a strong level of trust between myself and someone who works for } \\
\text { the organization }\end{array}$ & 0.706 & & & & & & \\
\hline \multicolumn{8}{|l|}{ Community Impact (3 items) } \\
\hline There are frequent events in the community organized by the team & & 0.871 & & & & & \\
\hline The team has a strong presence in the local community & & 0.819 & & & & & \\
\hline The community events organized by the team are of high quality & & 0.665 & & & & & \\
\hline \multicolumn{8}{|l|}{ School Programs (4 items) } \\
\hline $\begin{array}{l}\text { I, or my child, gain benefits from attending or participating in the team's } \\
\text { school programs }\end{array}$ & & & 0.957 & & & & \\
\hline The team often has programs in mine, or my child's school & & & 0.863 & & & & \\
\hline I, or my child, enjoy the team's school programs & & & 0.821 & & & & \\
\hline My team has a presence in mine, or my child's school & & & 0.817 & & & & \\
\hline \multicolumn{8}{|l|}{ Sport Participation (3 items) } \\
\hline Myself, or my child, participate in the sport & & & & 0.931 & & & \\
\hline Myself, or my child, enjoy playing the sport & & & & 0.894 & & & \\
\hline Myself, or my child, began playing the sport at a young age & & & & 0.788 & & & \\
\hline \multicolumn{8}{|l|}{ Unique Promotions (3 items) } \\
\hline I appreciate the unique promotions and giveaways my team offers & & & & & 0.782 & & \\
\hline My team has unique promotions & & & & & 0.705 & & \\
\hline My team has had promotions that I haven't seen other sport teams do & & & & & 0.655 & & \\
\hline
\end{tabular}


Table 1. Cont.

\begin{tabular}{|c|c|c|c|c|c|c|c|}
\hline Factors & F1 & F2 & F3 & F4 & F5 & F6 & F7 \\
\hline First Game Experience (3 items) & & & & & & & \\
\hline $\begin{array}{c}\text { The game operations (pre-game, scoreboard, intermission, entertainment) } \\
\text { was excellent at my first game }\end{array}$ & & & & & & 0.945 & \\
\hline $\begin{array}{l}\text { There was a high level of service quality at my team's venue at my first } \\
\text { game experience (concessions, cleanliness, parking, ect... ) }\end{array}$ & & & & & & 0.851 & \\
\hline Leading up to my first game experience I was very excited & & & & & & 0.584 & \\
\hline Team Success (4 items) & & & & & & & \\
\hline The team had a long winning streak the season I became a fan & & & & & & & 0.915 \\
\hline My team had a successful regular season the year I became a fan & & & & & & & 0.903 \\
\hline The team had a memorable playoff run the season I became a fan & & & & & & & 0.984 \\
\hline I remember a specific big win my team had the year I became a fan & & & & & & & 0.692 \\
\hline
\end{tabular}




\subsection{Reliability and Validity Estimates}

Cronbach's alpha scores were calculated for each of the seven factors in order to examine the reliability of the model. All of these scores were above the recommended cut-off value of 0.70 , signaling that the retained factors can be deemed reliable [41]. Additionally, the average variance extracted (AVE) for each factor was above the recommended value of 0.50 and the composite reliability for each factor was above the recommended value of 0.60 [43]. Lastly, no factor correlations exceed the suggested value of 0.85 , establishing discriminate validity (Table 2) [44]. All factor loadings were above the acceptable threshold of 0.50 , and most of them were larger than the desired level of 0.70 (Hair et al., 2010), confirming a good convergent validity of measurement scale. With these measures, the seven-factor, 24-item model can be deemed reliable for a newly developed scale. Table 2 includes a full report of all calculated values.

Table 2. Reliability and Validity Assessments.

\begin{tabular}{|c|c|c|c|c|}
\hline Factors & $\lambda$ & $\alpha$ & AVE & CR \\
\hline Individual Relationship (4 items) & & 0.91 & 0.65 & 0.88 \\
\hline Someone who works for the organization is available to me often & 0.881 & & & \\
\hline $\begin{array}{c}\text { There is regular communication between myself and someone who } \\
\text { works for the organization }\end{array}$ & 0.841 & & & \\
\hline $\begin{array}{l}\text { I have opportunities to meet/communicate with someone who works } \\
\text { for the organization }\end{array}$ & 0.798 & & & \\
\hline $\begin{array}{l}\text { There is a strong level of trust between myself and someone who works } \\
\text { for the organization }\end{array}$ & 0.706 & & & \\
\hline Community Impact (3 items) & & 0.89 & 0.63 & 0.83 \\
\hline There are frequent events in the community organized by the team & 0.871 & & & \\
\hline The team has a strong presence in the local community & 0.819 & & & \\
\hline The community events organized by the team are of high quality & 0.665 & & & \\
\hline School Programs (4 items) & & 0.95 & 0.75 & 0.92 \\
\hline $\begin{array}{c}\text { I, or my child, gain benefits from attending or participating in the } \\
\text { team's school programs }\end{array}$ & 0.957 & & & \\
\hline The team often has programs in mine, or my child's school & 0.863 & & & \\
\hline I, or my child, enjoy the team's school programs & 0.821 & & & \\
\hline My team has a presence in mine, or my child's school & 0.817 & & & \\
\hline Sport Participation (3 items) & & 0.89 & 0.76 & 0.91 \\
\hline Myself, or my child, participate in the sport & 0.931 & & & \\
\hline Myself, or my child, enjoy playing the sport & 0.894 & & & \\
\hline Myself, or my child, began playing the sport at a young age & 0.788 & & & \\
\hline Unique Promotions (3 items) & & 0.81 & 0.52 & 0.76 \\
\hline I appreciate the unique promotions and giveaways my team offers & 0.782 & & & \\
\hline My team has unique promotions & 0.705 & & & \\
\hline My team has had promotions that I haven't seen other sport teams do & 0.655 & & & \\
\hline First Game Experience (3 items) & & 0.83 & 0.65 & 0.84 \\
\hline $\begin{array}{c}\text { The game operations (pre-game, scoreboard, intermission, } \\
\text { entertainment) was excellent at my first game }\end{array}$ & 0.945 & & & \\
\hline $\begin{array}{l}\text { There was a high level of service quality at my team's venue at my first } \\
\text { game experience (concessions, cleanliness, parking, etc....) }\end{array}$ & 0.851 & & & \\
\hline Leading up to my first game experience I was very excited & 0.584 & & & \\
\hline Team Success (4 items) & & 0.90 & 0.77 & 0.93 \\
\hline The team had a long winning streak the season I became a fan & 0.915 & & & \\
\hline My team had a successful regular season the year I became a fan & 0.903 & & & \\
\hline The team had a memorable playoff run the season I became a fan & 0.984 & & & \\
\hline I remember a specific big win my team had the year I became a fan & 0.692 & & & \\
\hline
\end{tabular}




\subsection{Structural Equation Modeling}

Fit indices of SEM were at a good level: $\chi^{2}=670.517(p<0.001), \chi^{2} / d f=2.014$, RMSEA $=0.062(90 \%$ $\mathrm{CI}=0.055-0.068), \mathrm{CFI}=0.922, \mathrm{TLI}=0.898$, and $\mathrm{SRMR}=0.046$. Major relationship coefficients are listed in Table 3. Specifically, individual relationship had significant or marginally significant correlations with introduction to new fans $(\beta=0.100, p=0.059)$ and game attendance $(\beta=0.168, p<0.01)$; community impact had marginally significant correlations with city pride $(\beta=0.138, p=0.118)$ and game attendance $(\beta=0.161, p=0.096)$; school programs had a marginally significant correlation with city pride $(\beta=0.128, p=0.058)$; sport participation significantly correlated with sense of connection ( $\beta=0.193, p<0.01)$ and TV/Steaming consumption $(\beta=0.184, p<0.01)$; unique promotions significantly correlated with city pride $(\beta=0.281, p<0.01)$; first game experience significantly correlated with player attachment $(\beta=0.273, p<0.05)$, sense of connection $(\beta=0.262, p<0.05)$, and TV/Streaming consumption $(\beta=0.432, p<0.01)$; team success had a marginally significant correlation with game attendance $(\beta=-0.115, p=0.066)$. Together, all seven dimensions explained $23.5 \%$ of city pride, $12.2 \%$ of player attachment, $10.3 \%$ of introduction of new fans, $13.4 \%$ of sense of connection, $22.6 \%$ of TV/Streaming consumption, and $12.5 \%$ of game attendance, indicating a good nomological validity of the scale. Figure 1 shows the structural relationships between socialization factors and the associated consumption behavior outcomes.

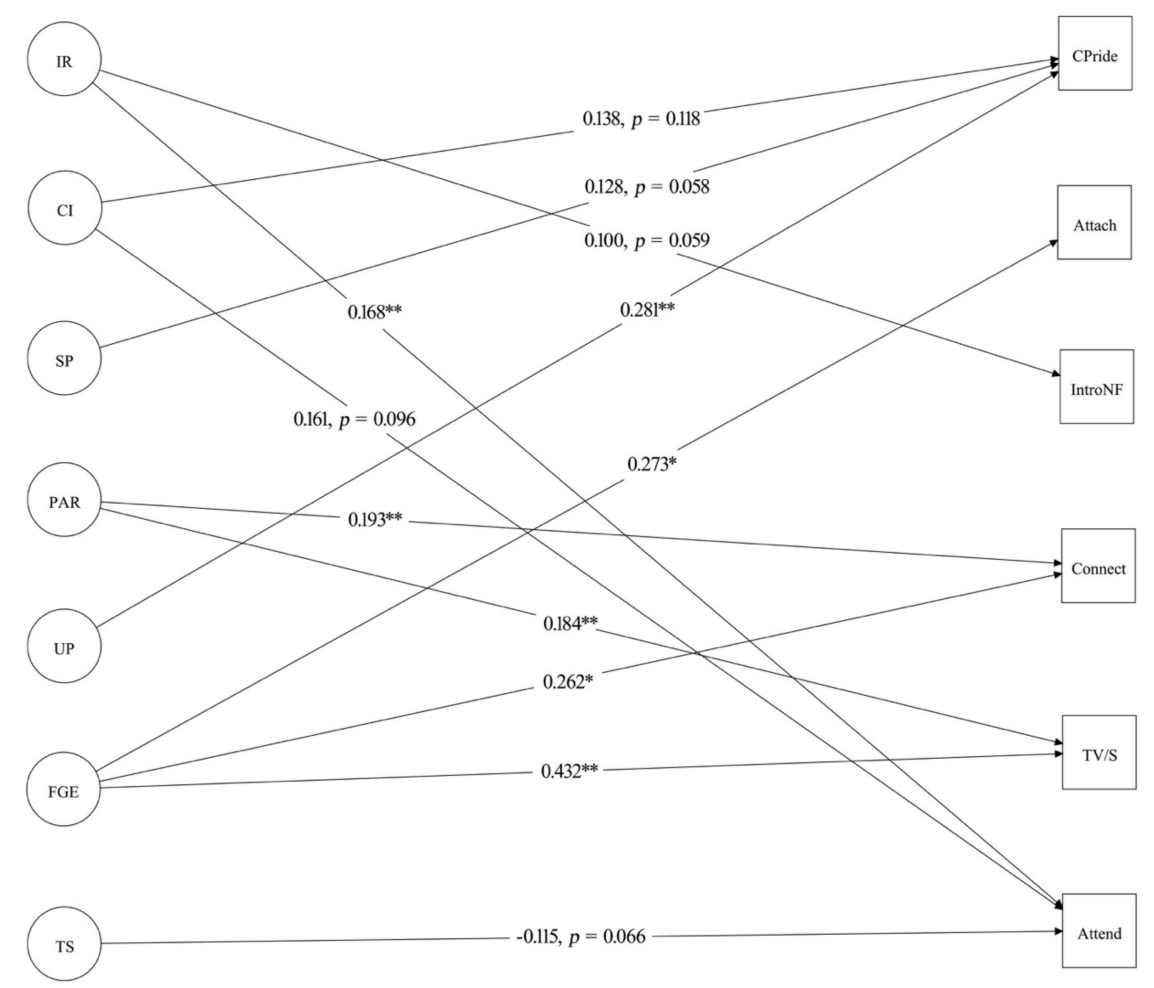

Figure 1. Structural relationships between socialization factors and consumption outcome variables. Notes. IR = Individual Relationship; CI = Community Impact; SP = School Programs; PAR = Sport Participation; UP = Unique Promotions; FGE = First Game Experience; TS = Team Success; CPrid = City Pride; Attch = Player Attachment; IntroNF = Introduce New Fans to the Team; Connect = Sense of Connection to the Fan Community; TV/S = TV/Steaming Consumption; Attend = Game Attendance. 
Table 3. Inter-Factor Correlations.

\begin{tabular}{lccccccc}
\hline \multicolumn{1}{c}{ Factor } & $\begin{array}{c}\text { Individual } \\
\text { Relationship }\end{array}$ & $\begin{array}{c}\text { Community } \\
\text { Impact }\end{array}$ & $\begin{array}{c}\text { School } \\
\text { Programs }\end{array}$ & $\begin{array}{c}\text { Sport } \\
\text { Participation }\end{array}$ & $\begin{array}{c}\text { Unique } \\
\text { Promotions }\end{array}$ & $\begin{array}{c}\text { First Game } \\
\text { Experience }\end{array}$ & $\begin{array}{c}\text { Team } \\
\text { Success }\end{array}$ \\
\hline Individual Relationship & & & & & & & \\
Community Impact & 0.275 & & & & & \\
School Programs & 0.355 & 0.403 & & & & \\
Sport Participation & 0.156 & 0.049 & 0.309 & & & \\
Unique Promotions & 0.239 & 0.585 & 0.219 & -0.046 & & \\
First Game Experience & 0.007 & 0.321 & 0.011 & -0.034 & 0.443 & 0.098 \\
Team Success & -0.086 & 0.169 & 0.056 & -0.148 & 0.150 & \\
\hline
\end{tabular}

\section{Discussion and Future Research}

\subsection{Discussion}

In a time of market saturation and increased pressure for sport organizations to develop fan bases in new areas [1], sport managers need to understand how individuals are socialized into fandom when traditional elements such as parents and media may not be as prominent. This is critical in sustaining successful business practices for sport organizations. Given the need for organizations to have a larger impact in socializing individuals in regions where that sport does not have a long-standing history, more research is needed looking at the impact team imitated socialization strategies have on developing a fan base in niche markets. Looking at the fan-initiated socialization vs the team-initiated socialization, these results suggest a departure from traditional socialization literature. Of the nine socialization factors conceptualized, seven factors were retained in this quantitative investigation. These factors are (a) local community affiliation, (b) sport participation, (c) individual relationship with the team, (d) school programs, (e) unique promotions, (f) team success, and (g) first game experience. The two that were dropped were 'influence from family and friends' and 'media exposure', tenants of previous socialization literature $[16,24]$.

This study was inspired from conceptual research on NHL fans in the Sunbelt, pushing forward research on fan socialization in niche markets $[4,20]$, who consider the idea that socialization into fandom may be different for those where a league or sport does not have a long-standing tradition. Considering there is a long history of sport fan socialization literature that find most socialization occurs from influences around the fan, outside the control of the organization $[17,18,22,47]$, it is interesting to find evidence that team-initiated socialization factors play a bigger role than fan-initiated factors for NHL fans in the Sunbelt. With these results, we do not suggest team-initiated socialization agents are the only factors that matter when it comes to sport fan socialization or that previous studies are irrelevant. What we do suggest is that team-initiated socialization agents are unacknowledged in sport management literature and need to be considered in attempts to better understand sport fans. This is especially the case for understanding the socialization of sport fans in niche markets because, as this study found, significant tenants of socialization research such as parental or media influence are not applicable.

A critical element of the results of this study noted that influence from family/friends or media exposure did not play a factor in the socialization of these fans, signaling a difference from previous socialization studies $[14,16,17]$. For influence from family or friends, this could be perhaps most fans of NHL teams in the Sunbelt are among the first generation of fans, as most teams began play within the last 25 years, making it unlikely someone is part of a family who has a long-standing tradition of being fans of that team. Additionally, as Hyatt, Kerwin, Hoeber and Sveinson [23] note, with a growing global technological landscape, children have access to communication technology their parents did not, giving them new socialization opportunities outside of their parents. In another departure from previous socialization literature, media exposure did not play a role in the socialization of these fans in this region. This is likely because most of the media attention is monopolized by larger, established sporting entities such as the NFL, NBA, MLB, and NCAA, making it difficult for sports such as hockey to get much airtime on mainstream media in these regions [8]. What follows is a 
discussion on the theoretical contributions to sport management literature and practical implications for industry practitioners.

\subsection{Team-Initiated Socialization Agents}

The results from this study empirically confirmed all the team-initiated strategies, showing how important team-initiated strategies are to the socialization of new fans in niche markets. These are elements that are totally within control of the organization, and if executed properly can work to strengthen the relationship between team and fan, creating a strong community of fans [48]. The first factor is creating an individual relationship with each fan. Those who felt this was a factor in their socialization felt a sense of connection to someone who worked for the organization and felt that someone from the organization would be available to them if needed. In business practices, relationship marketing has been at the core of many customer service philosophies, but in the sport context, previous research has shown this type of relationship can lead to increased consumer behaviors such as ticket and merchandise purchases [49,50], and this study highlights the importance of relationship marketing in socializing fans in niche markets. For this group of fans, a strong relationship with the organization led to increased game attendance and willingness to act as a socialization agent themselves and recruit others to become fans of the team. This supports the ideas from Dwyer, et al. [51] who note the importance of fans being advocates for the brand and for organizations to utilize existing fans to recruit new ones in niche markets.

School programs was the second of five team-initiated factors that led to fan socialization. Although some participants may not have been school age when becoming a fan, Mastromartino, Zhang and Wann [20] noted that sometimes parents would become socialized through the school programs of their child, supporting findings from Hyatt, Kerwin, Hoeber and Sveinson [23]. Participants felt that they or their child found school programs to be beneficial and provided value to them, contributing to their socialization as a fan of the team, specifically leading to an increased sense of civic pride. Influence from schools has been well established in previous research [17] and appears to be a strong tenant for fans in this region. Mastromartino, Zhang and Wann [20] note that sport managers for NHL teams in the Sunbelt region have made it a priority to partner with local schools and develop new fans through strategic partnerships, and sport leagues looking to expand to new geographic regions should make partnerships with schools a part of their fan development strategy.

Next, experience at the arena was found to be an influential socialization agent. Although a family member or friend can be the one to initiate a new fan attending their first game, the items associated with the first game experience have nothing to with do those who brought them. Specifically, it was the game operations (sights and sounds of the venue, intermission entertainment), service quality (concessions, cleanliness), and the anticipation build up before the game. As noted, without other fans, the new fan may never be in the arena in the first place, making this a fan-initiated socialization agent, but there are elements within this that are within the team's control. This study suggests that a positive first game experience may be the most critical factor in the socialization of fans as it was positively correlated with the most consumption outcomes: attachment to player(s), watching games on TV, and a sense of connection with the fan community. Items such as game operations and service quality have been noted as factors that contribute to consumer satisfaction and future purchase intentions [52], and now this study suggests they are important in socializing new fans where the sport is in a niche market.

Team performance has often been discussed as critical to sport fan socialization and consumption behaviors [19,53], sometimes even being identified as the most critical factor [26]. Although the actual performance of the team is outside the control of the marketing department, how they capitalize on team performance is within their control. Participants of this study noted minor successes such as a 'big win' or 'successful regular season' as items that they consider strong team performance, playing a role in their socialization as a fan. These items can be capitalized on by marketing managers through 
reminds of recent big wins, highlighting player milestones, and season recaps, even if the team does not win the championship.

Unique promotions were the final factor under team-initiated socialization factors. Organizations will often use promotions (price discounts, giveaways) as a way to gain awareness for their team [13]. However, for individuals of this region, it appears that a perception of uniqueness is important. This goes beyond traditional price discounts and suggests that something unique is needed for these promotions to act as a socialization agent. As noted in previous literature, it is key to identifying specific consumer segments and create different promotional strategies that appeal to each group [54]. For example, sport managers in Mastromartino, Zhang and Wann [20] discussed the idea that since they are in a non-traditional hockey market, they are not bound by a traditionalist hockey mentality and can think outside the box when it comes to creating promotions to attract fans. Developing promotions and giveaways that individuals perceive as unique are important in attracting new fans in this region.

\subsection{Fan-Initiated Socialization Agents}

Agents that are outside the control of the organization and largely dictated by other fans are considered agents that are fan-initiated [48]. For NHL fans in the Sunbelt, the two fan-initiated factors that played a role in being socialized into fandom were geographic community and playing experience.

Local community and geographic proximity was an important factor in understanding socialization of fans in niche markets. Although this factor is fan initiated as it is a result of the fan living in a specific location, the sport organization can implement strategies to appeal to the geographic pride some individuals may have. Specifically, it is the frequency and quality of community events that have played a role in making community to affect an integral part of fan socialization in this region. Although community has been found to be a socialization agent in previous socialization research $[28,55,56]$, the degree of importance of this agent has differed among geographic region and genders [24]. For fans of NHL teams in the Sunbelt region, local community was a socialization agent to their fandom and was correlated with increased civic pride and game attendance. This suggests that for teams of sports that are new to a geographic region, such as hockey in the southern U.S., it is vital for organizations to develop a presence in the local community with frequent and high-quality community events.

Sport participation was the other empirically tested socialization factor that this study suggests plays a large role in developing fans for a sport in a niche region. The link between participation and consumption has been discussed in previous literature [22,30]. However, this may be an issue for regions where the sport does not have a long standing tradition, such as hockey in the southern U.S. Developing the infrastructure for certain sports such as hockey can be challenging, and for parents, equipment costs can be a prohibitive roadblock to registering for hockey. However, managers interviewed in Mastromartino, Zhang and Wann [20] note that they need to get creative to build playing experience into their fan development strategy. Recognizing the challenges in building ice rinks and recruiting children to play, organizations would often run street hockey tournaments or clinics to educate people about the rules and traditions of the sport. In areas where developing infrastructure for the sport is challenging, sport organizations need to find creative ways to modify the sport that make it accessible for more people to be exposed to and participate in.

\subsection{Limitations and Suggestions for Future Research}

These results highlight the importance of this current study in that sport leagues that are attempting to develop fan bases in new or non-traditional areas cannot rely on traditional socialization agents such as influence from parents and media exposure. Sport organizations need to play a more hands-on role in developing a fan base in niche markets, and have more control in how they strategically build a fan base. In a way, this gives sports such as hockey in the southern U.S. a unique opportunity to expose their brand and grow the sport in ways teams in traditional markets cannot.

While the data collected in this study helps paint a picture of how sports fans in niche markets are socialized into fandom, the study has limitations. First, the responses from participants are 
retrospective in nature. Some participants may have been fans for over a decade, and recalling specific feelings, thoughts, and emotions from their time prior to being a fan could be a challenging task. Future research should look at the differences among participants by length of time as a fan and examine how that may affect their perceptions of their socialization experience. Additionally, future studies could take a longitudinal approach and document the experiences of fans going through the Psychological Continuum Model (PCM) in real time [18].

Second, this study utilized split-sample validation when conducting the EFA and CFA. Although this has been adopted in other scale development studies [57,58], this model could be further tested by utilizing two rounds of data collection for a more robust understanding of the model. Third, by recruiting fans of NHL teams, our focus was on professional sport in North America and we eliminate the ability to understand and analyze the socialization patterns of college sport fans and fans of other sports around the world. There are various factors such as attending a certain school that can impact socialization into college sports which is not applicable in the professional sport setting, and therefore these results may not be generalizable for understanding fans of college sport $[59,60]$. Future studies could examine the differences between socialization of professional sport fans and of college sport fans. Additionally, our sample is limited to the North American values and culture of sport fandom. Future research should test this model in various areas of the world as "it is important for research to conduct cross-cultural work to determine how the sport fan socialization process differs across various sociocultural contexts" [24].

Author Contributions: Conceptualization, B.M.; Data Curation, B.M.; Formal analysis, B.M. \& J.J.W.; Investigation, B.M. Methodology, J.J.W. \& B.M..; Software, J.J.W. \& B.M..; Writing-Original Draft Preparation, B.M. \& T.Y.Q.; Wring-Review \& Editing, B.M. \& T.Y.Q.; Project Administration, J.J.Z.; Supervision, J.J.Z. All authors have read and agreed to the published version of the manuscript.

Funding: There was no funding for this research.

Conflicts of Interest: The authors declare no conflicts of interest.

\section{References}

1. Gaines, C. Some U.S. Cities May Have Too Many Pro Sports Teams. Bus. Insid. 2013.

2. Mastromartino, B.; Chou, W.W.; Zhang, J.J. The Passion That Unites Us All: The Culture and Consumption of Sports Fans. In Exploring the Rise of Fandom in Contemporary Consumer Culture; Wang, C., Ed.; IGI Global: Hershey, PA, USA, 2018; pp. 52-70.

3. Johnson, L.M.; Chou, W.-H.W.; Mastromartino, B.; Zhang, J.J. Sport Fan Consumption: Contemporary Research and Emerging Trends. In Handbook of Research on the Impact of Fandom in Society and Consumerism; IGI Global: Hershey, PA, USA, 2019; pp. 149-170.

4. Mastromartino, B.; Wann, D.L.; Zhang, J.J. Skating in the sun: Examining identity formation of NHL fans in sunbelt states. J. Emerg. Sport Stud. 2019, 2, 1-25.

5. Miloch, K.S.; Lambrecht, K.W. Consumer awareness of sponsorship at grassroots sport events. Sport Mark. Q. 2006, 15, 147-154.

6. Titlebaum, P.; Lawrence, H.J. Perceived motivations for corporate suite ownership in the 'big four' leagues. Sport Mark. Q. 2010, 19, 88-96. [CrossRef]

7. Wyshynski, G. Southern-Fried Hockey: How Alabama Has Made the Sport Its Own. 2019. Available online: https://www.espn.com/nhl/story/_/id/25676183/hockey-alabama-where-unlikely-die-hards-meetdelightful-shenanigans (accessed on 3 February 2020).

8. Greenhalgh, G.P.; Simmons, J.M.; Hambrick, M.E.; Greenwell, T.C. Spectator support: Examining the attributes that differentiate niche from mainstream sport. Sport Mark. Q. 2011, 20, 41-52.

9. Greenhalgh, G.P.; Greenwell, T.C. Professional niche sports sponsorship: An investigation of sponsorship selection criteria. Int. J. Sports Mark. Spons. 2013, 14, 2-19. [CrossRef]

10. Dwyer, B.; Greenhalgh, G.; LeCrom, C. Niche-versus mainstream-sport spectators: An analysis of need for uniqueness and sport eFANgelism. Int. J. Sport Commun. 2016, 9, 364-383. [CrossRef]

11. Greenwell, T.C.; Greenhalgh, G.; Stover, N. Understanding spectator expectations: An analysis of niche sports. Int. J. Sport Manag. Mark. 2013, 13, 144-157. [CrossRef] 
12. Sutton, W.A.; McDonald, M.A.; Milne, G.R.; Cimperman, J. Creating and fostering fan identification in professional sports. Sport Mark. Q. 1997, 6, 15-22.

13. Funk, D.C.; James, J.D. Consumer loyalty: The meaning of attachment in the development of sport team allegiance. J. Sport Manag. 2006, 20, 189-217. [CrossRef]

14. James, J.D. The role of cognitive development and socialization in the initial development of team loyalty. Leis. Sci. 2001, 23, 233-261. [CrossRef]

15. Kolbe, R.; James, J.D. An identification and examination of influences that shape the creation of a professional team fan. Int. J. Sports Mark. Spons. 2000, 2, 14-28. [CrossRef]

16. Wann, D.L. The causes and consequences of sport team identification. In Handbook of Sports and Media; Raney, A.A., Jennings, B., Eds.; Lawrence Erlbaum Associates: Mahwah, NJ, USA, 2006; pp. 331-352.

17. McPherson, B.D. Socialization into the role of sport consumer: A theory and causal model. Can. Rev. Sociol./Rev. Can. Sociol. 1976, 13, 165-177. [CrossRef]

18. Funk, D.C.; James, J. The psychological continuum model: A conceptual framework for understanding an individual's psychological connection to sport. Sport Manag. Rev. 2001, 4, 119-150. [CrossRef]

19. Wann, D.L.; Tucker, K.B.; Schrader, M.P. An exploratory examination of the factors influencing the origination, continuation, and cessation of identification with sports teams. Percept. Mot. Ski. 1996, 82, 995-1001. [CrossRef]

20. Mastromartino, B.; Zhang, J.J.; Wann, D.L. A management perspective on fan socialization strategies: Marketing hockey to fans in sunbelt states. J. Brand Strategy 2020, in press.

21. Hickman, T.M. The impact of fan identification, purchase intentions, and sponsorship awareness on sponsors share of wallet. Sport Mark. Q. 2015, 24, 170.

22. Wann, D.L.; Schrader, M.P.; Wilson, A.M. Sport fan motivation: Questionnarie validation, comparisons by sport, and relationship to athletic motivation. J. Sport Behav. 1999, 22, 114.

23. Hyatt, C.G.; Kerwin, S.; Hoeber, L.; Sveinson, K. The reverse socialization of sport fans: How children impact their parents' sport fandom. J. Sport Manag. 2018, 32, 542-554. [CrossRef]

24. Wann, D.L.; James, J.D. Sport Fans: The Psychology and Social Impact of Fandom, 2nd ed.; Routledge: New York, NY, USA, 2019.

25. Gwinner, K.; Swanson, S.R. A model of fan identification: Antecedents and sponsorship outcomes. J. Serv. Mark. 2003, 17, 275-294. [CrossRef]

26. Aiken, K.D.; Koch, E.C. A conjoint approach investigating factors in initial team preference formation. Sport Mark. Q. 2009, 18, 81.

27. Groeneman, S. American's Sports Fans and Their Teams: Who Roots for Whom and Why; Seabird Press: Lexington, KY, USA, 2017.

28. Melnick, M.J.; Wann, D.L. Sport fandom influences, interests, and behaviors among Norwegian university students. Int. Sports J. 2004, 8, 1-13.

29. Phua, J.J. Sports fans and media use: Influence on sports fan identification and collective self-esteem. Int. J. Sport Commun. 2010, 3, 190-206. [CrossRef]

30. Tokuyama, S.; Greenwell, T.C. Examining similarities and differences in consumer motivation for playing and watching soccer. Sport Mark. Q. 2011, 20, 148-156.

31. Lee, S.; Heere, B.; Chung, K.-S. Which senses matter more? The impact of our senses on team identity and team loyalty. Sport Mark. Q. 2013, 22, 203-213.

32. Kelley, S.W.; Hoffman, K.D.; Carter, S. Franchise relocation and sport introduction: A sports marketing case study of the Carolina Hurricanes' fan adoption plan. J. Serv. Mark. 1999, 13, 469-480. [CrossRef]

33. Churchill, G.A. A paradigm for developing better measures of marketing constructs. J. Mark. Res. 1979, 16, 64-73. [CrossRef]

34. Hardesty, D.M.; Bearden, W.O. The use of expert judges in scale development. J. Bus. Res. 2004, 57, 98-107. [CrossRef]

35. Andrew, D.P.; Pedersen, P.M.; McEvoy, C.D. Research Methods and Design in Sport Management; Human Kinetics: Champaign, IL, USA, 2011.

36. Creswell, J.W. Research Design: Qualitative, Quantitative, and Mixed Methods Approaches; Sage Publications: Newbury Park, CA, USA, 2013.

37. Fabrigar, L.R.; Wegener, D.T.; MacCallum, R.C.; Strahan, E.J. Evaluating the use of exploratory factor analysis in psychological research. Psychol. Methods 1999, 4, 272-299. [CrossRef] 
38. Kaiser, H.F. A second generation little jiffy. Psychometrika 1970, 35, 401-415. [CrossRef]

39. Zwick, W.R.; Velicer, W.F. Factors influencing four rules for determining the number of components to retain. Multivar. Behav. Res. 1982, 17, 253-269. [CrossRef] [PubMed]

40. Kaiser, H.F. An index of factorial simplicity. Psychometrika 1974, 39, 31-36. [CrossRef]

41. Nunnally, J.C.; Bernstein, I.H. Psychometric Theory; McGraw-Hill: New York, NY, USA, 1994.

42. Hu, L.; Bentler, P.M. Cutoff criteria for fit indexes in covariance structure analysis: Conventional criteria versus new alternatives. Struct. Equ. Modeling A Multidiscip. J. 1999, 6, 1-55. [CrossRef]

43. Fornell, C.; Larcker, D.F. Evaluating structural equation models with unobservable variables and measurement error. J. Mark. Res. 1981, 18, 39. [CrossRef]

44. Kline, R. Methodology in the social sciences. In Principles and Practice of Structural Equation Modeling, 2nd ed.; Guilford Press: New York, NY, USA, 2005.

45. Hair, J.F., Jr.; Babin, B.J.; Anderson, R.E. Multivariate Data Analysis: A Global Perspective, 7th ed.; Prentice Hall: Englewood Cliffs, NJ, USA, 2010.

46. Bollen, K.A. Structural Equation Models with Observed Variables. Struct. Equ. Latent Var. 1989, $28,80-150$.

47. Wann, D.L. Understanding the positive social psychological benefits of sport team identification: The team identification-social psychological health model. Group Dyn. Theory Res. Pract. 2006, 10, 272-296. [CrossRef]

48. Jang, H.; Olfman, L.; Ko, I.; Koh, J.; Kim, K. The influence of on-line brand community characteristics on community commitment and brand loyalty. Int. J. Electron. Commer. 2008, 12, 57-80. [CrossRef]

49. Kim, Y.K.; Trail, G.; Ko, Y.J. The influence of relationship quality on sport consumption behaviors: An empirical examination of the relationship quality framework. J. Sport Manag. 2011, 25, 576-592. [CrossRef]

50. Tsiotsou, R.H. Sport team loyalty: Integrating relationship marketing and a hierarchy of effects. J. Serv. Mark. 2013, 27, 458-471. [CrossRef]

51. Dwyer, B.; Greenhalgh, G.P.; LeCrom, C.W. Exploring fan behavior: Developing a scale to measure sport eFANgelism. J. Sport Manag. 2015, 29, 642-656. [CrossRef]

52. Murray, D.; Howat, G. The relationships among service quality, value, satisfaction, and future intentions of customers at an Australian sports and leisure centre. Sport Manag. Rev. 2002, 5, 25-43. [CrossRef]

53. Fisher, R.J.; Wakefield, K. Factors leading to group identification: A field study of winners and losers. Psychol. Mark. 1998, 15, 23-40. [CrossRef]

54. Funk, D.C. Consumer-based marketing: The use of micro-segmentation strategies for understanding sport consumption. Int. J. Sports Mark. Spons. 2002, 4, 39-64. [CrossRef]

55. Theodorakis, N.D.; Wann, D.; Al-Emadi, A.; Lianopoulos, Y.; Foudouki, A. An examination of levels of fandom, team identification, socialization processes, and fan behaviors in Qatar. J. Sport Behav. 2017, 40, 87-107.

56. Parry, K.D.; Jones, I.; Wann, D.L. An examination of sport fandom in the United Kingdom: A comparative analysis of fan behaviors, socialization processes, and team identification. J. Sport Behav. 2014, 37, 251.

57. Byon, K.K.; Zhang, J.J.; Connaughton, D.P. Dimensions of general market demand associated with professional team sports: Development of a scale. Sport Manag. Rev. 2010, 13, 142-157. [CrossRef]

58. Qian, T.Y.; Zhang, J.J.; Wang, J.J.; Hulland, J. Beyond the game: Dimensions of Esports online spectator demand. Commun. Sport 2019. [CrossRef]

59. Trail, G.T.; Kim, Y.K. Factors influencing spectator sports consumption: NCAA women's college basketball. Int. J. Sports Mark. Spons. 2011, 13, 55-77. [CrossRef]

60. Allen, J.T.; Drane, D.; Byon, K. Gender differences in sport spectatorship among college baseball fans. Int. J. Sport Manag. 2010, 11, 418-439.

(C) 2020 by the authors. Licensee MDPI, Basel, Switzerland. This article is an open access article distributed under the terms and conditions of the Creative Commons Attribution (CC BY) license (http://creativecommons.org/licenses/by/4.0/). 